\title{
A New Method of Blood Galactose Estimation for Mass Screening of Galactosemia
}

\author{
Yushin Fujimura, Masahiko Kawamura* and Hiroshi \\ NARUSE $\dagger$ \\ Department of Microbiology, Nagoya City Public Health \\ Institute, Nagoya 467, *Clinic of Pediatrics, Meijo Hospital, \\ Nagoya 460, and $\uparrow$ National Center for Nervous, Mental and \\ Muscular Diseases, Kodaira $18 \%$
}

\begin{abstract}
Fujimura, Y., Kawamura, M. and Naruse, H. A New Method of Blood Galactose Estimation for Mass Screening of Galactosemia. Tohoku J. exp. Med., 1981, 133 (4), 371-378 — A new method for quantitative determination of galactose in blood by fluorescence of NADH was described. The assay system consisted of $\beta$-galactose dehydrogenase, NAD, buffer and a denatured blood disc ( $3 \mathrm{~mm}$ diameter), and the reaction was carried out for $1 \mathrm{hr}$ at $37^{\circ} \mathrm{C}$. Denaturation of hemoglobin was accomplished by exposing the blood disc to a vapor of formic acid in an air-tight container; this procedure completely eliminated false positive cases of galactosemia. This method can be applied in a wide range of galactose concentration from low $(0 \mathrm{mg} \%)$ to high levels $(200-1,000 \mathrm{mg} \%)$ with the accuracy of $8.0 \pm 0.3 \mathrm{mg} \%$ from a coefficient of variation of $3.5 \%$. Semi-quantitative assay was also possible by using a spot test like Beutler's method. The galactose content in one disc paper ( $3 \mathrm{~mm}$ diameter) of blood containing $5 \mathrm{mg} \%$ galactose is approximately $0.1 \mu \mathrm{g}$. The newly developed method is satisfactorily applicable in neonatal mass screening and clinical cases. galactose; mass screening of galactosemia; $\beta$-galactose dehydrogenase; fluorometry
\end{abstract}

Gal occupies an important place in carbohydrate metabolism, and it serves as an efficient metabolite in various hepatic diseases, galactosemia and galactokinase deficiency. Notably, Rommel's method (Rommel et al. 1968) has thus far been accepted as a workable technique in Gal determination. The technique, however, has proved inadequate for mass screening in that it requires perchloric acid for deproteinization and a spectrophotometer. Moreover, it requires relatively large quantities of blood specimen and is time-consuming. In the field of galactosemia screening, Beutler's method (Beutler and Baluda 1966) and Paigen's method modified by Guthrie (personal communication) are widely used currently, but both of them suffer from defects. In the former, a high incidence of false positive of galactosemia occurs which results from inactivation of the enzyme during mailing

Received for publication, April 12, 1980.

Reprint requests: Masahiko Kawamura, M.D., Clinic of Pediatrics, Meijo Hospital, 1-3-1 Sannomaru, Naka-ku, Nagoya 460.

The following abbreviations were used: GADH, $\beta$-galactose dehydrogenase; NAD, nicotine adenine dinucleotide; NADH, reduced nicotine adenine dinucleotide; Gal, galactose; Gal-1-P, galactose-1-phosphate; UDP-Gal uridine diphosphate galactose. 
and preservation of test materials under a high temperature and humidity.

On the other hand, we found that Paigen's method determines not only Gal but the related compounds such as UDP-Gal, Gal-1-P and lactose (unpublished). Thus, development of a new technique to determine Gal exclusively has been awaited. Previously we reported (Fujimura et al. 1977a, b) a semi-quantitative spot test of galactose which is a modification of the method of Rommel et al. and uses approximately one-hundredth the volume of blood sample required in the original procedure. The minimum levels of Gal which could be determined by our method ranged 10 to $20 \mathrm{mg} \%$. When combined with the denaturation of hemoglobin, the range of the newly developed assay expanded to cover the range from $6-8 \mathrm{mg} \%$ to $1,000 \mathrm{mg} \%$. Then, this technique was further improved so as to be applicable to mass screening for galactosemia using only a single 3-mm Guthrie test filter paper which was impregnated with a minute amount of blood specimen from the neonate or adult. Moreover, the assay system, which is based on fluorospectrophotometry, quantitatively eliminates false positive reactions frequently encountered by Beutler's method and the Paigen's method modified by Guthrie.

The present paper describes the new method devised by the authors and some results obtained by the application of this technique to neonatal mass screening and clinical cases.

\section{Materials and Methods}

Specimen. Standard paper discs for blood galactose assay: Fresh blood samples collected at fasting before meal were left in a refrigerator $\left(0-4^{\circ} \mathrm{C}\right)$ overnight, and hematocrit was adjusted to $50-60 \%$. Next, given amounts of Gal were added into the blood, and each of the following blood specimens containing no Gal added (nearly $0 \mathrm{mg} \%$ by galactose kit, Boehringer Mannhiem), 2, 4, 6, 8, 10, 12, 20, 30, 50, 75, 100, 200, 300, 500, 700 and $1,000 \mathrm{mg} \%$ of Gal were dripped onto Guthrie's test paper (made by Daiichi Kagaku Co.). The samples were then dried in air to prepare the standard samples.

General test materials: Neonatal blood filter papers (blood samples should not be autoclaved) sent in for Guthrie's test were used.

False positive cases by Beutler's test: Thirty blood samples selected from false positive cases by mass screening tests for galactosemia, with the procedure of Beutler and Baluda (1966), were studied.

Positive and false positive cases by Paigen's test: Thirty-five blood samples positive or false positive for Gal by Paigen's test were studied. The Gal levels by Paigen's test were over $20 \mathrm{mg} \%$ in 3 blood samples, $12 \mathrm{mg} \%$ in 3,12 to $8 \mathrm{mg} \%$ in $5,8 \mathrm{mg} \%$ in 4 , and 6 to $8 \mathrm{mg} \%$ in 20 .

Hemoglobin denaturation treatment. Each sample filter paper obtained as above was cut into dises of $3 \mathrm{~mm}$ diameter to be placed in the hemoagglutination tray for TPHA (non-fluorescent, made by Tominaga Co.) or the microtiter trays (either Cook's V type or disposable tray $\mathrm{V}$ type, $125 \mathrm{~mm} \times 14 \mathrm{~mm}, 96$ holes). The discs were kept free for $1 \mathrm{hr}$ in an air-tight glass container saturated with formic acid vapor. The trays were taken out, and placed in a desiccator so that acid could be removed. Then, the desiccator was evacuated by suction and placed in an incubator kept at $37^{\circ} \mathrm{C}$ for a few hr to overnight for removal of acid. Samples thus obtained did not liberate hemoglobin into solution at all.

Principle of the test. The test is a modification of the method of Rommel et al. (1968), utilizing GADH which reacts specifically with Gal, as previously described (Fujimura et al. 1977a, b). 
Quantitative assay. Reaction system. Reagent system 1: This represents the complete reagent system and consists of $10 \mu \mathrm{l}$ of $13 \mathrm{mM} \mathrm{NAD} \mathrm{(10} \mathrm{mg/ml,} \mathrm{from} \mathrm{Boehringer),}$ $10 \mu \mathrm{l}$ of $0.35 \mathrm{M}$ phosphate buffer $(\mathrm{pH} 8.0$ ), $10 \mu \mathrm{l}$ of a $1: 100$ dilution of $5 \mathrm{mg} / \mathrm{ml}$ GADH (Boehringer, code No. 104981) solution and one blood-impregnated $3 \mathrm{~mm}$ paper disc which has been treated for hemoglobin denaturation. Reagent system 2: Similar to Reagent system 1 except that $10 \mu \mathrm{l}$ of distilled water were used in place of GADH. Reagent system 3: Similar to Reagent system 1 except that $10 \mu \mathrm{l}$ of distilled water were used in place of NAD. Reagent system 4: Similar to Reagent system 1 except that the bloodimpregnated paper disc (specimen) was omitted. These reagent systems were placed in small test tubes, respectively, stoppered, and incubated at $37^{\circ} \mathrm{C}$ for $1 \mathrm{hr}$.

Galactose assay by fluorospectrometry. After $1 \mathrm{hr}$ of incubation at $37^{\circ} \mathrm{C}, 3 \mathrm{ml}$ of distilled water were added to each tube to terminate the reaction and fluorescent transmittance of each mixture at excitation wavelength of $340 \mathrm{~nm}$ and emission wavelength of $450 \mathrm{~nm}$ was recorded by a Shimazu fluorospectrometer model 502 or a Hitachi fluorospectrometer model 204, with the reference reading for $1.17 \mu \mathrm{g}$ quinine sulfate (Katayama Chemicals; $8.4 \mathrm{mg}$ in $10,000 \mathrm{ml}$ of $0.01 \mathrm{M}$ phosphate buffer, $\mathrm{pH} \mathrm{7.4)}$ adjusted to $100 \%$ transmittance. For estimation of low concentration of Gal (0-30 mg\%), the fluorometry was made using a quinine sulfate reference of lower concentration $(0.29 \mu \mathrm{M}$ or $8.4 \mathrm{mg}$ in $40,000 \mathrm{ml}$ of $0.01 \mathrm{M}$ phosphate buffer, $\mathrm{pH} 7.4$ ) adjusted to $100 \%$ transmittance.

Concentration and activity of GADH. GADH stock solution was diluted to $1: 10,1: 100$, $1: 200,1: 500,1: 1,000,1: 2,000,1: 5,000$, and $1: 10,000$ with $0.35 \mathrm{M}$ phosphate buffer. The Gal assay was performed by using $10 \mu \mathrm{l}$ of each of the dilution enzyme solutions.

Time course of reaction. Blood Gal assays were carried out in the complete reagent system with a $3-\mathrm{mm} 100 \mathrm{mg} \%$ Gal blood discs, and fluorescence was read at 10, 20, 30, 45, 60,90 and $120 \mathrm{~min}$ of incubation. $95 \%$ of maximal activity was obtained at $10 \mathrm{~min}$ and $100 \%$ at $20 \mathrm{~min}$ of incubation.

Error in Gal assay by the present method. Eight pieces of discs ( $3 \mathrm{~mm}$ diameter) were, at random, punched out from a standard blood paper containing $5 \mathrm{mM} \mathrm{Gal}$, and treated for denaturation of hemoglobin. Gal assays were performed with these dises and fluorometric transmittance of the mean Gal concentration $\bar{X}$, standard deviation S.D. and coefficient of variation $C . V .(\%)=$ s.D. $/ \bar{X}$ were calculated.

Semiquantitative spot test. A total of $30 \mu \mathrm{l}$ of the reaction mixture composed of $10 \mu \mathrm{l}$ of $13 \mathrm{mM}$ NAD, $10 \mu \mathrm{l}$ of buffer $(\mathrm{pH} 6.0-8.0$ ) and $10 \mu \mathrm{l}$ of 300 - to 500 -fold diluent of $5 \mathrm{mg} / \mathrm{ml}$ stock solution of GADH, was placed in a microtiter tray where a blood disc (denatured) had been placed. The top of the tray was sealed with tape to prevent drying, and the mixture was allowed to react for $1 \mathrm{hr}$ at $37^{\circ} \mathrm{C}$. Then, the mixture was spotted on the Watmann No. 1 filter paper as in Beutler's method. Following air dry, the fluorescence strength was determined under irradiation of excitation light at $365 \mathrm{~nm}$ or $253 \mathrm{~nm}$ or both, using a fluorescence detector, Superlight SL-DI (from Nikko Sekiei K.K.) and using the standard fluorescence references consisting of the various ratios of NADH/NAD mixture (Fujimura et al. 1976).

\section{REsults}

\section{Hemoglobin denaturation by formic acid or acetic acid}

Since hemoglobin interferes with the determination of NADH fluorescence, factors leading to denaturation of hemoglobin were studied. Hemoglobin on the disc was exposed to vapor of formic acid at various saturations and found to be completely denaturated when exposed for $1 \mathrm{hr}$ to vapors at higher than $33 \%$. Furthermore, when the discs with denatured hemoglobin as processed as described in Methods section were incubated with the assay mixture at $37^{\circ} \mathrm{C}$, the final $\mathrm{pH}$ remained to be 7.6-8.0, showing no appreciable decline. Acetic acid was not so good as formic acid since it was not easy to completely eliminate remaining acid. 


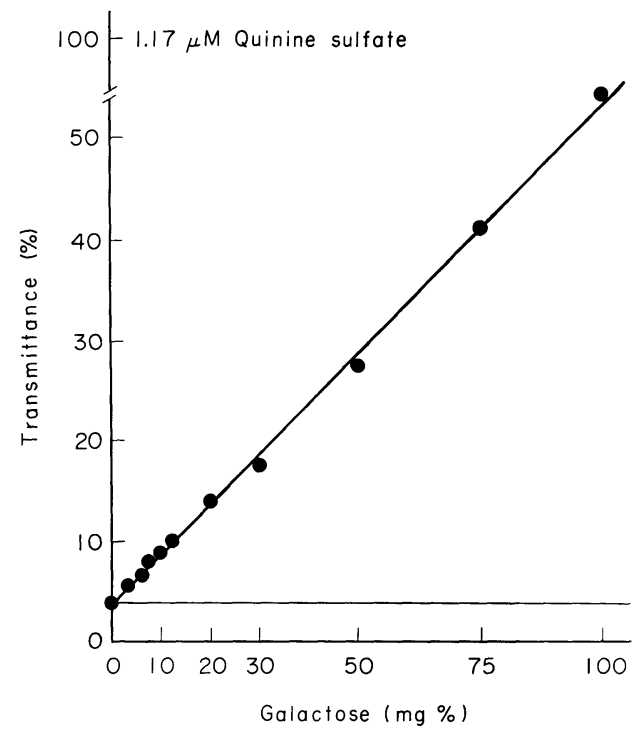

(A)

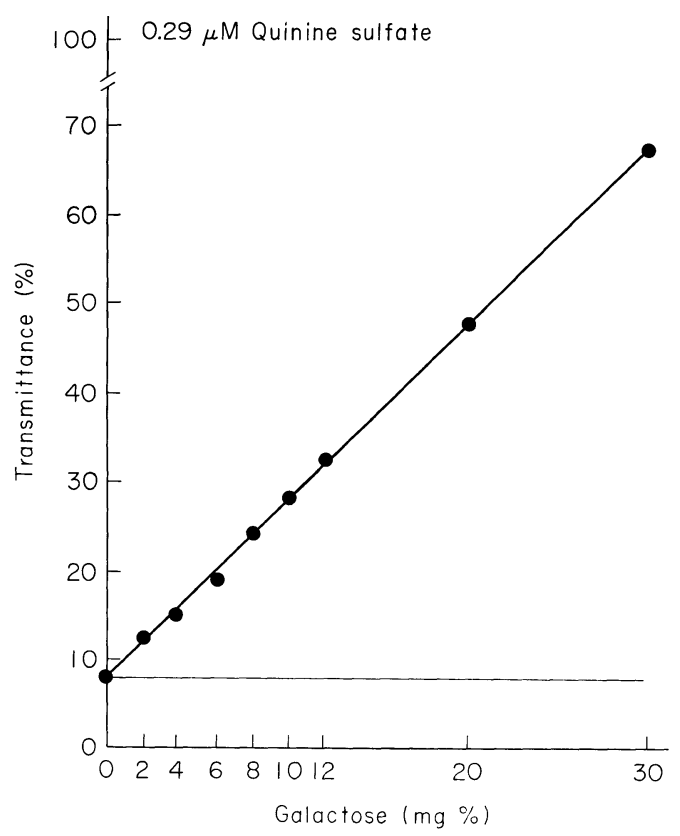

(B)

Fig. 1. Standard curves of galactose quantification. The standard galactose blood discs $(0-100 \mathrm{mg} \%$ in $\mathrm{A})$ and $(0-30 \mathrm{mg} \%$ in $\mathrm{B})$ were quantified in Reaction system 1. GADH was omitted in the control system. $1.17 \mu \mathrm{M}(\mathrm{A})$ and $0.29 \mu \mathrm{M}(\mathrm{B})$ of quinine sulfate were the references and their fluorescences were adjusted to $100 \%$, respectively.

Preparation of calibration curves with standard blood discs for Gal assay

The fluorometric estimation of blood galactose was conducted with Reagent systems 1 to 4 , using hemoglobin-denatured discs containing $0,2,4,6,8,10,12,20$, 30, 50, 75 and $100 \mathrm{mg} \%$ Gal. Reagent systems 2, 3 and 4 served as the controls. As can be seen in Fig. 1-A, a linear plot of fluorescent transmittance was obtained against the Gal concentrations from 0 to $100 \mathrm{mg} \%$. It was possible to scale up the difference of system 1 minus system 2 in $0-30 \mathrm{mg} \%$ of Gal by adjusting the reference with $0.29 \mu \mathrm{M}$ quinine sulfate to $100 \%$ transmittance (Fig. 1-B).

\section{Concentration and activity of GADH}

In Fig. 2 are shown the results obtained with various concentrations of GADH at a fixed concentration $(75 \mathrm{mg} \%)$ of Gal on the blood disc. The enzymatic activity fell drastically at dilutions beyond 1:1000, and the values at 1:100 and 1:1000 dilutions of the enzyme were somewhat higher than the activity obtained for the undiluted enzyme stock solution. When the assay was carried out with blood-impregnated paper discs containing $20 \mathrm{mg} \%$ Gal, however, the enzyme activity of GADH was not appreciably decreased even at the 1:1000 dilution. The activity of GADH was not significantly lost when the disc preparation was left at $0-4{ }^{\circ} \mathrm{C}$ for one week (Fig. 2). 
Fig. 2. Concentration and activity of GADH. Stock solution of GADH was $5 \mathrm{mg} / \mathrm{ml}$. In the assay with galactose blood of $75 \mathrm{mg} \%$ (०---), $1.17 \mu \mathrm{M}$ quinine sulfate was the reference and in the assay with the galactose blood of $20 \mathrm{mg} \%$ $(\Delta-\cdot-), 0.29 \mu \mathrm{M}$ quinine sulfate. The activity of GADH stored at $0-4^{\circ} \mathrm{C}$ for one week $(\bullet-)$ was examined using the galactose blood of $75 \mathrm{mg} \%$.

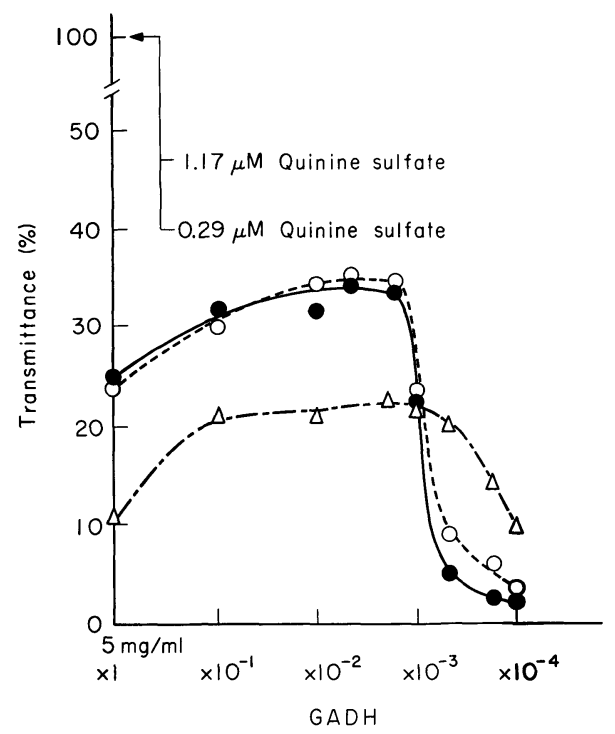

TABLE 1. Deviation in assay by authors' method

\begin{tabular}{|c|c|c|c|c|c|c|c|c|}
\hline & \multicolumn{8}{|c|}{ Dise No. } \\
\hline & 1 & 2 & 3 & 4 & 5 & 6 & 7 & 8 \\
\hline \multirow{4}{*}{$\begin{array}{c}X(\%) \\
X-\bar{X}(\%)\end{array}$} & 62.5 & 58.5 & 61.5 & 55.5 & 58.5 & 60.5 & 59.5 & 59.5 \\
\hline & +3.0 & -1.0 & +2.0 & -4.0 & -1.0 & +1.0 & 0 & 0 \\
\hline & \multicolumn{2}{|c|}{$\bar{X}=59.5(\%)$} & \multicolumn{5}{|c|}{$\sqrt{\frac{\Sigma(X-\bar{X})^{2}}{n}}=2.1$} & \\
\hline & $C . V .(\%$ & $=\frac{\text { S.D. }}{\bar{X}}$ & $=3.5 \%$ & \multicolumn{4}{|c|}{$S . A .=8.0 \pm 0.3 \mathrm{mg} \%$} & \\
\hline
\end{tabular}

s.D., standard deviation; $\bar{X}$, mean of $X ; C . V$., coefficient of variation; S.A., sensitivity of assay.

\section{Error in assay}

The extent of error in the measurement of blood Gal content by the present assay method was examined by repeating the assay with the same specimens (Table 1). A mean fluorescent transmittance $(\bar{X})$ of 59.5 was obtained for eight discs impregnated with blood containing $100 \mathrm{mg} \%$ Gal. The standard deviation (s.D.) was calculated to be 2.1 and the coefficient of variation $(C . V .=$ s.D. $/ \bar{X})$ was $3.5 \%$; hence the measured values being within a 5 per cent range of error. This method was in the accuracy and the sensitivity of $8.0 \pm 0.3 \mathrm{mg} \%$ of Gal. The results indicate usefulness of the assay method.

Blood Gal assay in false positive cases by Beutler's test

Blood samples from 30 patients found to be false positive for galactosemia by 
Beutler's test were assayed by the present method. As shown in Fig. 3, the blood Gal level was less than $4 \mathrm{mg} \%$, being by far lower than the lower limit of the positive range, in all the 30 cases studied.

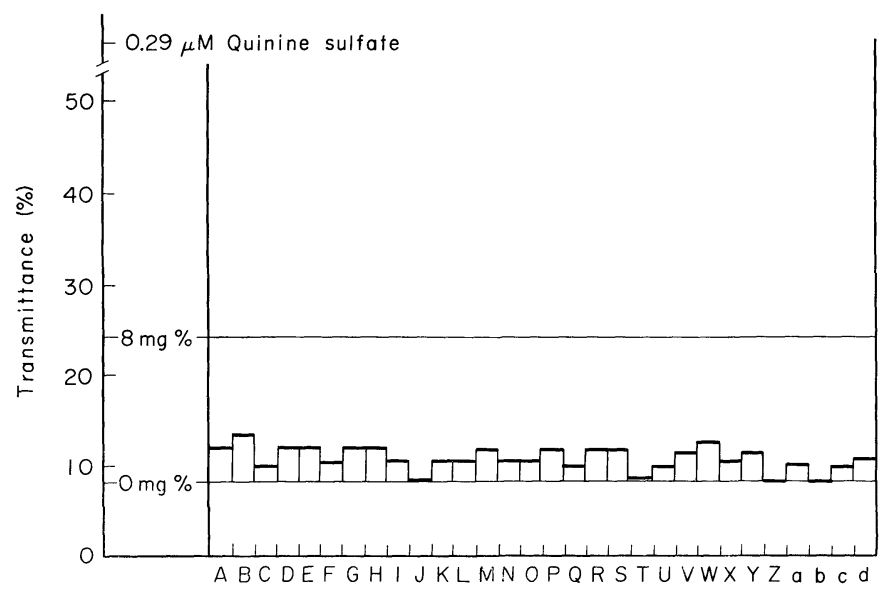

Fig. 3. Re-examination by the present method of galactose levels of false positive cases detected by Beutler's method. A,B,C, -..., etc. are false positive cases by Beutler's method.

TABLE 2. Comparison of blood galactose assays between Paigen's and the authors' methods

\begin{tabular}{|c|c|c|c|c|c|c|c|c|c|c|c|c|c|}
\hline \multicolumn{14}{|c|}{ Blood galactose $(\mathrm{mg} \%)$} \\
\hline $\begin{array}{l}\text { Paigen's } \\
\text { method }\end{array}$ & $>20>20>20$ & 12 & 12 & 12 & $8-12$ & $8-12$ & $8-12$ & $8-12$ & 8 & 8 & 8 & 8 & $6-8$ \\
\hline $\begin{array}{l}\text { Authors' } \\
\text { method }\end{array}$ & $50.425 .7 \quad 10.1$ & 2.3 & 2.5 & 3.4 & 2.8 & 4.0 & 2.3 & 2.1 & 1.0 & 1.3 & 1.6 & 1.2 & 1.5 \\
\hline
\end{tabular}

Blood Gal assay in false positive cases by Paigen's test

In the Paigen-Guthrie method, determination involved not only Gal but Gal-1-P, UDP-Gal and lactose in some cases. With this in mind, some of the cases proved as positive or false-positive by Paigen's test were studied by our method. In three cases of liver diseases in which the blood Gal value was over $20 \mathrm{mg} \%$ by Paigen's test, the assay by our method revealed concentrations of $10.1,25.7$ and $50.4 \mathrm{mg} \%$, respectively, as shown in Table 2. Three patients showing blood Gal levels of 12 $\mathrm{mg} \%$ and five patients showing 8 to $12 \mathrm{mg} \%$ by Paigen's test were all shown to be entirely normal with values between 2 and $4 \mathrm{mg} \%$ by the present test. It was found that the blood Gal content returned to normal levels in all these cases sent in after a few weeks by re-examination of the Paigen's method. In 4 cases displaying $8 \mathrm{mg} \%$ of Gal in the blood and in 20 cases showing 6 to $8 \mathrm{mg} \%$, the tests by the author's method were all normal. 


\section{Discussion}

The new method of Gal quantification which we have developed is characterized by simplicity and expediency of the procedure that is comparable to Beutler's method (Beulter and Baluda 1966); the method uses Guthrie's test filter paper so that blood can be sucked and the blood test material can be sent by mail for investigation.

Another advantage inherent in authors' technique is that the technique is free from a high incidence of false positive cases of galactosemia due to enzymatic inactivation which might occur during mailing or preservation of blood. Still another merit may come from expediency which allows direct measurement of Gal itself. The new technique is suitable and valuable as the mass screening method because the amount of blood required is so small; about 1/100 that needed in Rommel's technique (Rommel et al. 1968). Tengström and Wranne (1968) and Tengström (1969) introduced an assay system with galactose oxidase (de Verdier and Hjelm, 1962) using paper discs as the carrier for blood specimen for estimation of blood Gal by an autoanalyzer. However, their method requires a disc diameter of not less than $14 \mathrm{~mm}$ which is practically unsuitable for mass screening by the Guthrie test. Grenier and Laberge (1973) reported a mass screening method of fluorometric determination of NADH for estimation of Gal levels with GADH using blood-impregnated paper dises of $7.94 \mathrm{~mm}$ in diameter. This size of the disc seems to be still oversized for mass screening. It has been pointed out that assays by the procedure of Grenier and Laberge (1973) are unreliable unless the test is repeated at least twice on the same specimen; this is probably because the measurement is interfered with by a high degree of nonspecific fluorescence arising from hemoglobin and reagents. We have experienced a similar phenomenon in the initial state of development of the present assay system.

Statistical data analysis revealed a remarkably low coefficient variation, $3.5 \%$, in the estimation of error in the assay by the present method, providing evidence for potential usefulness of this assay method.

The enzyme GADH exhibited sufficiently high activities at dilutions up tr approximately 1:1,000 in phosphate buffer when assessed using a $5 \mathrm{mg} / \mathrm{ml}$ enzyme stock solution. Therefore, we decided to use a 1:100 dilution of the stock solution in the assay system in anticipation for adequate margins of safety. When the stock solution was tested without dilution, the activity obtained was significantly lower than those obtained with the 1:10 and 1:100 dilutions (Fig. 2). Probably this is due to inhibition caused by high contents of ammonium sulfate in the stock solution.

By using our method, several blood samples diagnosed as false positive by Beutler's test were shown to be normal with Gal values of less than $4 \mathrm{mg} \%$. The majority of cases in which Paigen's tests were false positive for galactosemia were also found to be normal by both the present and clinical methods. In the Gal tolerance test, too, Paigen's method appears to produce a higher value than the real value quantified by Rommel's method, whereas the test by the authors' 
method yields value which is close to that obtained by the Rommel's. Thus, our method may be valuable for eliminating such frequently encountered false positive reactions in mass screening. The incidence of "false positive" in the assay by the present method may probably be at a level lower than $1 / 6000$, this is reported by Grenier and Laberge (1973).

\section{References}

1) Beutler, E. \& Baluda, M.C. (1966) A simple spot screening test for galactosemia. J. Lab. clin. Med., 68, 137-141.

2) de Verdier, C.H. \& Hjelm, M.A. (1962) A galactose oxidase method for the determination of galactose in blood plasma. Clin. chim. Acta, 7, 742-744.

3) Grenier, A. \& Laberge, C. (1973) Rapid method for screening for galactosemia and galactokinase deficiency by measuring galactose in whole blood spotted on paper. Clin. Chem., 19, 463-465.

4) Fujimura, Y., Yonezawa, S. \& Sato, T. (1976) Mass screening for inborn errors of metabolism. VII. Improvement of new simple micro quantitative method of galactose determination and its practical approach for mass screening. Annual Papers of Nagoya Cith Public Health Institute, 23, 15-21. (Japanese)

5) Fujimura, Y., Yonezawa, S., Sato, T. \& Kawamura, M. (1977a) Mass screening for inborn errors of metabolism. II. Simple micro semi-quantitative method of galactose determination in blood and urine by fluorescence Jap. J. Pediat., 30, 1521-1526 (Japanese)

6) Fujimura, Y., Yonezawa, S., Sato, T. \& Kawamura, M. (1977b) Mass screening for inborn errors of metabolism. III. Simple micro semi-quantitative method of galactose determination in blood and urine by fluorescence, and its practical application to patients. Jap. J. Pediat., 30, 1527-1528. (Japanese)

7) Rommel, K., Bernt, E., Schmitz, F. \& Grimmel, K. (1968) Enzymatische Galactosebestimmung in Blut und oraler Galactose-Toleranztest. Klin. Wschr., 46, 936-940.

8) Tengström, B. \& Wranne, L. (1968) Sugars in blood and urine of milk-fed normal young infants. Scand. J. clin. Lab. Invest., 22, 137-141.

9) Tengström, B. (1969) Automated blood galactose analysis as a screening method for galactosemia in milk-fed newborns. Scand. J. clin. Lab. Invest., 23, 197-200. 